\title{
Family Members of Cancer Patients in Korea Are at an Increased Risk of Medically Diagnosed Depression
}

\author{
Youngdae Cho ${ }^{1,2,3}$, Yongwoo Jeon ${ }^{1,3}$, Sung-In Jang ${ }^{1,2,3}$, Eun-Cheol Park ${ }^{1,2,3}$ \\ ${ }^{1}$ Department of Preventive Medicine, Yonsei University College of Medicine, Seoul, Korea; ${ }^{2}$ Institute of Health Services Research, Yonsei University \\ College of Medicine, Seoul, Korea; ${ }^{3}$ Department of Public Health, Yonsei University Graduate School, Seoul, Korea
}

Objectives: Family members are often cancer patients' primary source of social and emotional support and make a major contribution to how well patients manage their illness. We compared the prevalence of depression in the family members of cancer patients and the general population.

Methods: This study used the data from the fourth, fifth, and sixth rounds of the Korea National Health and Nutrition Examination Survey. The variable of interest was the presence of a cohabitating cancer patient in the family and the dependent variable was the presence of diagnosed depression.

Results: The odds of having medically diagnosed depression in those with a cohabitating cancer patient in the family were signifcantly higher than among those who did not have cancer patients in their families (odds ratio [OR], 1.56; 95\% confidence interval [Cl], 1.12 to $2.17 ; p=0.009)$. The $\mathrm{OR}$ for females was 1.59 , and this increase was statistically significant $(95 \% \mathrm{Cl}, 1.09$ to $2.31 ; p=0.02)$.

Conclusions: We need to invest more effort into diagnosing and managing depression in the family members of cancer patients. This will have an impact both on their quality of life and on the well-being of patients, as supporters and caregivers play an instrumental role in helping patients manage their illness.

Key words: Neoplasms, Family, Caregivers, Depression

\section{INTRODUCTION}

Cancer is a major cause of mortality worldwide, causing 8.2 million deaths in 2012 [1]. Advances in diagnosis and treatment over recent decades have led to improved survival rates in developed countries [2]. However, the burden of cancer remains significant, as approximately 14.1 million new cancer

Received: October 18, 2017 Accepted: January 31, 2018

Corresponding author: Eun-Cheol Park, MD, PhD Department of Preventive Medicine, Yonsei University College of Medicine, 50-1 Yonsei-ro, Seodaemun-gu, Seoul 03722, Korea E-mail: ecpark@yuhs.ac

This is an Open Access article distributed under the terms of the Creative Commons Attribution Non-Commercial License (http://creativecommons.org/licenses/by$\mathrm{nc} / 4.0 /$ ) which permits unrestricted non-commercial use, distribution, and reproduction in any medium, provided the original work is properly cited. cases worldwide occurred in 2012 [3], and an estimated 196.3 million years of healthy life were lost in 2013 because of cancer [4].

A cancer diagnosis has a significant impact not only on the patient, but also on his or her family members [5]. Typically, family caregivers ( $F C s$ ) are patients' primary source of social and emotional support and make a major contribution to how well patients manage their illness [5-8]. Therefore, the physical, emotional, and practical problems faced by family members are very significant issues [9].

FCs often experience a decline in physical health, personal welfare, and well-being, including an increase in psychological distress and a decline in mental health $[10,11]$. Previous studies have suggested that FCs experience more depression and anxiety than non-caregivers [5,12]. According to Edwards and 
Clarke [13], depression may decrease caregivers' quality of life (QoL) and impair their ability to care for the cancer patient. Therefore, they suggest that attention should be focused on depression and anxiety not only in patients, but in all family members. In this context, Lee et al. [14] demonstrated that early screening and management of depression in caregivers could improve their QoL and capability to care for patients.

In Korea, a number of studies have focused on the FCs of cancer patients. Park et al. [15] determined the prevalence and identified predictors of anxiety and depression among FCs of patients with cancer. In addition, they reported that FCs with anxiety or depression were at a high risk for suicide [9]. Yoon et al. [16], in an investigation of modifiable factors associated with the burdens faced by the FCs of cancer patients in Korea, reported that the time spent providing care was a modifiable risk factor. Song et al. [17] showed that the FCs of patients with terminal cancer experienced mental health problems and deterioration of health-related QoL. Moreover, in an analysis using Beck Depression Inventory scores, Rhee et al. [18] showed a high prevalence of depression in the FCs of cancer patients.

However, few studies have investigated depression in the family members of cancer patients. Diagnosed depression incurs actual medical costs for the family of the cancer patient, so it could be more meaningful than undiagnosed depression. Unlike previous studies, the present study used physician-diagnosed depression as the dependent variable [19].

The ongoing increase in cancer, with the consequent increase in the number of family members of cancer patients, is also a very important problem. In this study, we did not limit the analysis to FCs, but expanded the scope somewhat to analyze entire cohabitating families. Using nationally representative data, this research compared the prevalence of depression diagnoses in the family members of cancer patients with the prevalence in the general population.

\section{METHODS}

\section{Data Source and Study Population}

This study used data from the fourth, fifth, and sixth rounds of the Korea National Health and Nutrition Examination Survey (KNHANES IV-VI, 2007-2014), which is a national survey conducted annually by the Korea Centers for Disease Control and Prevention (KCDC). The survey, which aims to assess the health status and the health-related perceptions and behav- iors of Koreans, provides reliable and representative results from the national, municipal, and provincial levels. All survey respondents provided written informed consent, and the institutional review board of Yonsei University Graduate School of Public Health approved the study (no. 2016-413-01).

This survey included a total of 30500 households over an 8-year period, and targeted all family members older than 1 year of age. Of the 65973 subjects in the initial dataset (male: 29 956; female: 36 017), we first excluded 15879 subjects who were less than 19 years old. Participants who did not respond to the survey question regarding diagnosed depression $(\mathrm{n}=$ 4316) were excluded. Cancer patients $(n=1596)$ and 1-person households $(n=5115)$ were also excluded from the analysis to reflect the effects on the 'family' itself. Finally, we excluded subjects with relevant missing values for the independent variables $(n=1159)$, resulting in a final study population of 38126 (male: 16 808; female: 21 318).

\section{Dependent Variable}

The outcome variable was the presence of diagnosed depression. The KNHANES inquiry regarding diagnosed depression was "Have you ever been diagnosed with depression by a doctor?" and the response choices were binary (yes or no).

\section{Family Members of Cancer Patients (Variable of Interest)}

We identified cancer patients as those who were diagnosed with any type of cancer during their lifetime by a physician. People who had the same household ID as those subjects were defined as family members of cancer patients. Subjects for whom no family member had a history of cancer diagnosis were defined as not being family members of cancer patients. In the KNHANES, family members who do not live together are not included as members of the same household; therefore, they were not naturally included in this study. As an additional analysis, the period from the cancer diagnosis and the type of cancer were further analyzed to more closely account for cancer patient characteristics.

\section{Covariates}

The independent variables included sex, age group, family income, educational level, number of family members, marital status, jobs, self-reported health condition, the presence of underlying chronic disease, and the study year. Age was used as a continuous variable in previous research $[11,12]$, but we 
divided participants by age into 6 categories (19-29, 30-39, 40$49,50-59,60-69$, and 70 years or older). The family income variable was categorized into 4 quartiles, adjusted by family size. Educational level was categorized into 4 groups (graduation from university or higher, graduation from high school, graduation from middle school, and graduation from elementary school). Participants were categorized by their number of family members into 3 groups (2, 3, or 4 or more family members). Marital status was categorized as married, separated or divorced, and single. Participants were divided into 2 groups according to employment status. Self-reported health condition was classified as good, usual, or bad. Underlying disease was considered to be present if the respondent had been diagnosed with hypertension, diabetes, stroke, heart disease, arthritis, or chronic renal disease by a doctor. Most variables had statistically significant associations with diagnosed depression.

\section{Statistical Analysis}

The data analysis was conducted using the chi-square test for the comparison of demographic, socioeconomic, and health-related factors between the groups. Odds ratios (ORs) with $95 \%$ confidence intervals ( $\mathrm{Cls}$ ) were calculated using multiple logistic regression to identify factors with a significant relationship with diagnosed depression by sex. Moreover, a set of subgroup analyses were performed to identify the independent effects of socioeconomic factors.

The statistical analysis was carried out on the weighted data using the SURVEYFREQ and SURVEYLOGISTIC procedures in SAS version 9.4 (SAS Institute Inc., Cary, NC, USA). The $p$-values $<0.05$ were considered to indicate statistical significance.

\section{RESULTS}

Table 1 shows the general characteristics of the 38126 subjects according to whether the subjects were family members of a cancer patient (family members of a cancer patient: 1590; subjects without a cancer patient in the family: 36 536). The percentages were weighted to be representative of the national population. The proportion of males who were members of a family with a cancer patient was higher than the proportion of females by approximately $15.2 \%$, and the proportion of females in families without cancer patients was slightly predominant. Age distribution, family income, educational level, and marital status differed between the groups, with no
Table 1. General characteristics of the study population according to the presence of a cancer patient within the family in the Korea National Health and Nutrition Examination Survey, 2007-2014 $(n=38$ 126)

\begin{tabular}{|c|c|c|c|}
\hline \multirow{2}{*}{ Variables } & \multicolumn{3}{|c|}{ Family member of a cancer patient } \\
\hline & No $(n=36$ 536) & Yes $(n=1590)$ & $p$-value \\
\hline Sex & & & $<0.001$ \\
\hline Male & $15997(50.5)$ & $811(57.6)$ & \\
\hline Female & 20539 (49.5) & $779(42.4)$ & \\
\hline Age (y) & & & $<0.001$ \\
\hline $19-29$ & $4797(20.2)$ & $280(29.0)$ & \\
\hline $30-39$ & $7771(22.8)$ & $226(16.5)$ & \\
\hline $40-49$ & $7561(23.5)$ & $170(13.6)$ & \\
\hline $50-59$ & $6690(17.3)$ & $288(17.5)$ & \\
\hline $60-69$ & $5508(9.5)$ & $340(12.7)$ & \\
\hline$\geq 70$ & $4209(6.7)$ & $286(10.6)$ & \\
\hline Family income & & & 0.005 \\
\hline First quartile (low) & 5809 (12.8) & $326(15.5)$ & \\
\hline Second quartile & $9439(26.4)$ & $411(27.6)$ & \\
\hline Third quartile & $10628(30.7)$ & $383(24.6)$ & \\
\hline Fourth quartile (high) & $10660(30.2)$ & $470(32.3)$ & \\
\hline Educational level & & & 0.001 \\
\hline Elementary school & $8104(15.6)$ & $432(18.3)$ & \\
\hline Middle school & $3909(9.7)$ & $191(9.9)$ & \\
\hline High school & $13208(41.0)$ & 475 (34.9) & \\
\hline College school & $11315(33.7)$ & $492(36.9)$ & \\
\hline No. of family members & & & 0.31 \\
\hline 2 & $12535(30.1)$ & $584(27.5)$ & \\
\hline 3 & $9694(29.0)$ & $404(29.2)$ & \\
\hline$\geq 4$ & $14307(40.9)$ & $602(43.3)$ & \\
\hline Marital status & & & $<0.001$ \\
\hline Married & $28727(73.0)$ & 1151 (60.9) & \\
\hline Separated or divorced & $2780(6.3)$ & $71(3.9)$ & \\
\hline Single & 5029 (20.7) & $368(35.2)$ & \\
\hline Job status & & & 0.09 \\
\hline Employed & $22404(65.3)$ & $947(62.8)$ & \\
\hline Unemployed & $14132(34.7)$ & $643(37.2)$ & \\
\hline Self-rated health & & & 0.63 \\
\hline Good & 13363 (37.4) & $550(37.2)$ & \\
\hline Common & $16253(46.1)$ & $712(45.2)$ & \\
\hline Bad & $6920(16.5)$ & $328(17.6)$ & \\
\hline Underlying chronic disease ${ }^{1}$ & & & 0.008 \\
\hline No & $25781(77.1)$ & $1002(74.1)$ & \\
\hline Yes & $10755(22.9)$ & 588 (25.9) & \\
\hline Study year & & & 0.04 \\
\hline 2007 & $2323(6.5)$ & $62(4.0)$ & \\
\hline 2008 & $5421(13.3)$ & $210(11.2)$ & \\
\hline 2009 & $6120(13.8)$ & $251(13.0)$ & \\
\hline
\end{tabular}


Table 1. Continued from the previous page

\begin{tabular}{|c|c|c|c|}
\hline \multirow{2}{*}{ Variables } & \multicolumn{3}{|c|}{ Family member of a cancer patient } \\
\hline & No $(n=36536)$ & Yes $(n=1590)$ & $p$-value \\
\hline 2010 & $5151(13.7)$ & $240(14.4)$ & \\
\hline 2011 & $4881(13.7)$ & $234(15.3)$ & \\
\hline 2012 & $4459(13.3)$ & $209(13.9)$ & \\
\hline 2013 & 4293 (13.3) & $179(12.5)$ & \\
\hline 2014 & $3888(12.4)$ & $205(15.6)$ & \\
\hline Diagnosed with depression & & & 0.03 \\
\hline No & $35203(96.7)$ & $1512(95.4)$ & \\
\hline Yes & $1333(3.3)$ & $78(4.6)$ & \\
\hline Weighted n & 30087761 & 1206633 & \\
\hline
\end{tabular}

Values are presented as number (weighted \%).

${ }^{1}$ Hypertension, diabetes, stroke, heart disease, arthritis, and chronic renal disease.

statistically significant trends. No significant differences in the number of family member or job status were found between the 2 groups. The prevalence of chronic diseases was slightly higher in the family members of cancer patients (22.9 vs. 25.9\%)

Table 2 shows the results for all variables adjusted for in the multivariate logistic regression analysis. The family members of cancer patients had higher odds of having been diagnosed with depression than those who did not have cancer patients in the family $(\mathrm{OR}, 1.56 ; 95 \% \mathrm{Cl}, 1.12$ to $2.17 ; p=0.009)$. When stratified by sex, only female family members (OR, 1.59; $95 \%$ $\mathrm{Cl}, 1.09$ to $2.31 ; p=0.02$ ) of cancer patients had increased odds of having been diagnosed with depression. This relationship was not significant in males $(\mathrm{OR}, 1.52 ; 95 \% \mathrm{Cl}, 0.83$ to 2.80 ; $p=0.18$ ). Based on the results of all adjusted variables, females who did not complete college had significantly higher odds of having been diagnosed with depression than those who graduated from university (OR for high school level, 1.61; $95 \% \mathrm{Cl}$, 1.29 to $2.02 ; p<0.001$ ), as was the case for females who were not employed (OR, $1.27 ; 95 \% \mathrm{Cl}, 1.09$ to $1.48 ; p=0.003)$ in comparison to those who were employed. When females had a small number of family members (OR for 2 family members, $1.29 ; 95 \% \mathrm{Cl}, 1.05$ to $1.58 ; p=0.01$ ) or were separated/divorced (OR, 1.48; $95 \% \mathrm{Cl}, 1.18$ to $1.85 ; p=0.001$ ), their odds of having been diagnosed with depression were significantly increased. No statistically significant association with the odds of having been diagnosed with depression was found with income and comorbidities.

Table 3 shows the associations between being a family member of a cancer patient and having been diagnosed with depression by family income, educational level, and the number of family members. Females with the highest family income had the highest odds of having been diagnosed with depression (OR, 2.30; 95\% Cl, 1.10 to $4.81 ; p<0.05)$ and females within a 2-person family had the highest risk of having been diagnosed with depression $(\mathrm{OR}, 2.01 ; 95 \% \mathrm{Cl}, 1.18$ to 3.42; $p<0.05$ ).

The Table S1 and S2 present further analyses of the effects of the cancer-related characteristics of cancer patients both in the study subjects as a whole and only in the family members of cancer patients. The highest odds of having been diagnosed with depression were found in family members of cancer patients more than 5 years after the diagnosis, but this trend was not statistically significant. The results were similar for various types of cancer.

\section{DISCUSSION}

This research, utilizing data from a nationwide survey in Korea, compared the prevalence of doctor-diagnosed depression in people with and without cancer patients in their families. In the present study, we found that the family members of people with cancer had a higher risk of having been diagnosed with depression than those who did not have cancer patients in their family.

Psycho-emotional disorders such as depression or anxiety have been reported to be typical problems for the family members of cancer patients. Family members follow the course of the disease, suffering comparable or even greater distress than the patients $[13,20]$. Previous studies reported that depression in the family members of cancer patients was associated with factors such as caregiving stress, patient symptoms, sleep loss, and caregiving burden [18,21-24]. In addition to those factors, several studies reported that depression in caregivers was related to the prediction of depression using the integrated QoL [25].

Large-scale domestic studies of the family members of cancer patients have used the same KNHANES 2007-2009 surveys and the 2012 Korea Community Health Survey $[26,27]$. Lim et al. [26] analyzed 565 family members of cancer patients with a control group constructed using 1:4 matching, but in the multivariate analyses, no significant results were found for any psychosocial impacts. Han [27] studied 8585 cases with 1:1 matching of controls, and found that the family members of cancer survivors had more depressive symptoms than the 
Table 2. Multiple logistic regression analysis of the presence of diagnosed depression by sex

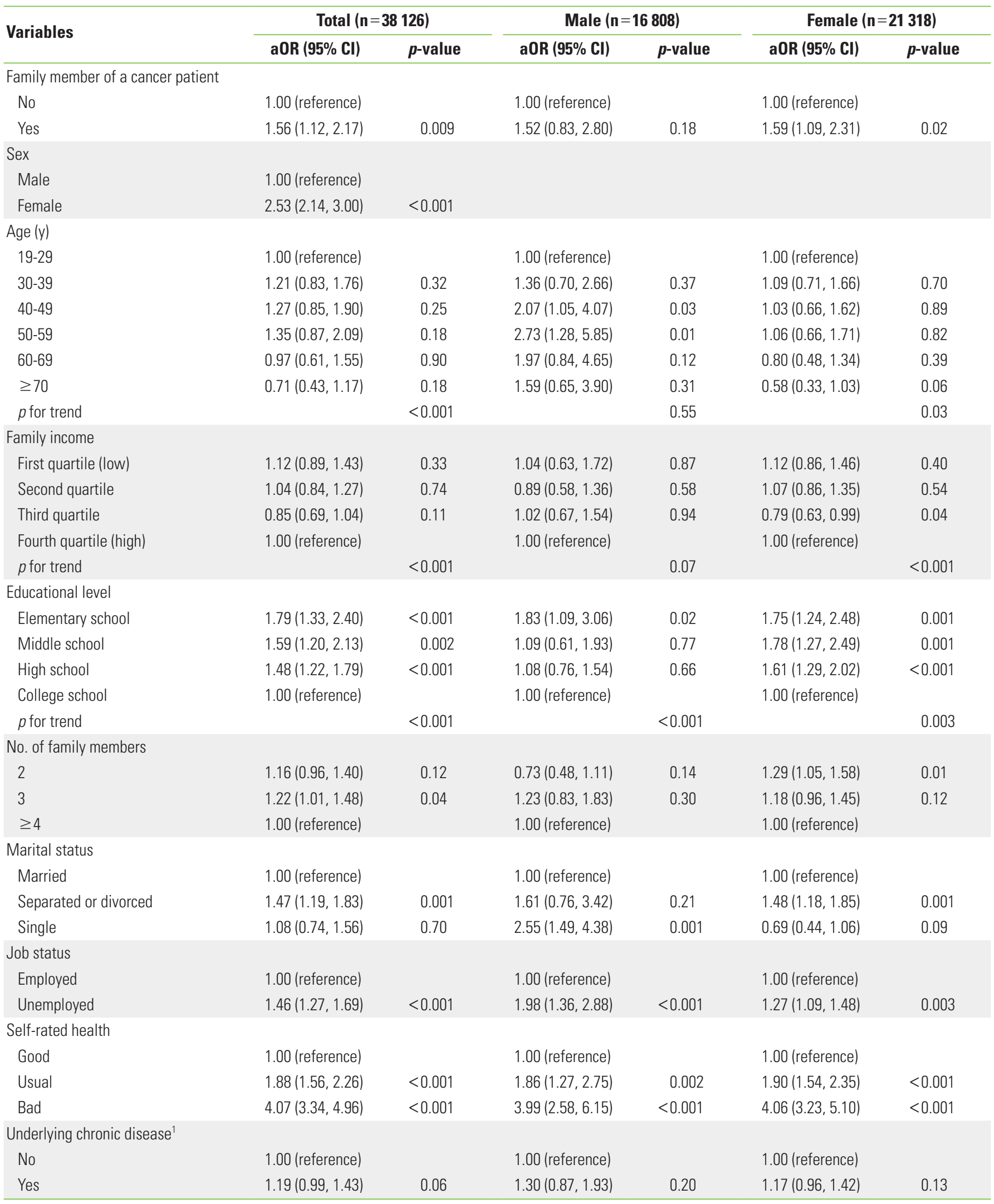


Table 2. Continued from the previous page

\begin{tabular}{|c|c|c|c|c|c|c|}
\hline \multirow{2}{*}{ Variables } & \multicolumn{2}{|c|}{ Total $(n=38$ 126) } & \multicolumn{2}{|c|}{ Male $(n=16808)$} & \multicolumn{2}{|c|}{ Female $(n=21318)$} \\
\hline & aOR (95\% Cl) & $p$-value & aOR (95\% Cl) & $p$-value & aOR (95\% Cl) & $p$-value \\
\hline \multicolumn{7}{|l|}{ Study year } \\
\hline 2008 & $1.18(0.83,1.69)$ & 0.35 & $0.80(0.39,1.62)$ & 0.53 & $1.38(0.92,2.07)$ & 0.13 \\
\hline 2009 & $1.38(0.97,1.96)$ & 0.07 & $1.16(0.61,2.20)$ & 0.65 & $1.48(0.99,2.22)$ & 0.06 \\
\hline 2012 & $1.66(1.16,2.38)$ & 0.006 & $1.25(0.62,2.55)$ & 0.53 & $1.85(1.23,2.79)$ & 0.003 \\
\hline 2013 & $1.56(1.10,2.22)$ & 0.01 & $1.41(0.72,2.77)$ & 0.32 & $1.63(1.08,2.46)$ & 0.02 \\
\hline 2014 & $2.28(1.58,3.27)$ & $<0.001$ & $1.75(0.88,3.49)$ & 0.11 & $2.51(1.66,3.79)$ & $<0.001$ \\
\hline$p$ for trend & & $<0.001$ & & 0.005 & & 0.001 \\
\hline
\end{tabular}

aOR, adjusted odds ratio; $\mathrm{Cl}$, confidence interval.

${ }^{1}$ Hypertension, diabetes mellitus, stroke, heart disease, arthritis, and chronic renal disease.

Table 3. Subgroup ${ }^{1}$ analysis of the association of being a family member of a cancer patient with the presence of diagnosed depression by socioeconomic variables

\begin{tabular}{lcc}
\hline Variables & Male $(\mathbf{n}=\mathbf{1 6}$ 808) & Female $(\mathbf{n}=\mathbf{2 1} \mathbf{3 1 8})$ \\
\hline Family income & & \\
First quartile (low) & $2.38(0.84,6.77)$ & $0.96(0.47,1.96)$ \\
Second quartile & $0.43(0.11,1.73)$ & $2.10(1.12,3.95)^{*}$ \\
Third quartile & $1.91(0.59,6.20)$ & $0.89(0.45,1.74)$ \\
Fourth quartile (high) & $1.66(0.62,4.48)$ & $2.30(1.10,4.81)^{*}$ \\
Educational level & & \\
Elementary school & $3.55(1.54,8.20)^{*}$ & $1.54(0.99,2.41)$ \\
Middle school & $<0.01(<0.01,<0.01)^{*}$ & $0.72(0.29,1.79)$ \\
High school & $0.51(0.16,1.65)$ & $1.68(0.89,3.18)$ \\
College school & $2.04(0.75,5.58)$ & $1.56(0.52,4.67)$ \\
No. of family members & & \\
2 & $1.79(0.55,5.86)$ & $2.01(1.18,3.42)^{*}$ \\
3 & $1.57(0.59,4.16)$ & $1.46(0.58,3.68)$ \\
$\geq 4$ & $1.08(0.44,2.67)$ & $1.19(0.65,2.20)$ \\
\hline
\end{tabular}

Values are presented as adjusted odds ratio ( $95 \%$ confidence interval).

${ }^{1}$ Each set of subgroup data was stratified by the selected variables, and adjusted for other variables (age group, family income, educational level, number of family members, marital status, job status, self-rated health, underlying chronic disease, and study year).

${ }^{*} p<0.05$.

controls (stress: adjusted OR [aOR], 1.08; depressive symptoms: aOR, 1.31). Although our study used somewhat different covariates, our results were generally consistent with those of previous studies, and we also demonstrated for the first time a sex effect on this relationship.

The prevalence of diagnosed depression was $3.33 \%$ among all subjects, corresponding to a prevalence of $4.60 \%$ among the family members of cancer patients was $4.60 \%$ and a prev- alence of $3.28 \%$ among their counterparts. According to the 2011 Epidemiological Survey of Mental Disorders in Korea, the prevalence of having experienced depression was $6.7 \%$ (male: 4.8\%; female: 9.1\%) [28]. Compared to previous studies investigating depression in the FCs of cancer patients, a relatively low prevalence was found in this study (Grunfeld et al. [29]: $11 \%$ for males and 12\% for females; Yang et al. [30]: 63.5\%; Chung et al. [31]: 27.5\%; Braun et al. [24]: 38.9\%). Some studies have found that the rate of depression in families was over $80 \%$ in self-response questionnaires [15,32]. Since the subjects of this study encompassed the entire family, not only caregivers, the prevalence was not remarkably low in comparison to the rates reported by previous studies.

After stratifying the subjects by gender, no statistically significant association remained between the presence of cancer patients in the family and diagnosed depression in males. However, a statistically significant relationship was found in females. This result is congruent with previous studies that reported differences in the caregiver burden based on sex, as the burden of caregiver duties in females may be greater than in males [33]. However, some studies reported that the difference in the caregiver's burden depending on sex was not statistically significant. Therefore, the differences in these results may be influenced by cultural differences in sex roles within the family [34]. According to the recent report of Kim et al. [35], the traditional caregivers in Korea are females-daughters, daughters-in-law and spouses - and they continue to play an important caregiving role despite the introduction of public long-term care insurance [35].

Although the modifying effect of household income and 
educational level on the association between being a family member of a cancer patient and depression was not significant, differences were observed in the OR according to the number of family members. The OR for depression became stronger as the number of family members decreased. This tendency suggests that individuals in 2-person households are more sensitive to disease within the family. Even when controlling for marital status, this trend appears to have been due to the fear of becoming isolated after bereavement and the pressure of caregiving responsibilities. Previous studies have not analyzed respondents according to the number of household members; given recent findings regarding depression in single-person households, this issue requires special attention [36].

The present study has several limitations. First, this study did not consider certain variables related to cancer patients, such as the type of cancer and the seriousness and duration of the disease. In addition, the variable of the caregiver's burden was not measured or adjusted for. The results may have differed depending on those variables. If the results were adjusted for patient-specific variables or the caregiver's burden, the ORs for having been diagnosed with depression might have been different. Therefore, the results in this study might have been influenced by the non-inclusion of several variables. In an additional analysis, when we added the variables of cancer type and period from diagnosis, the OR of depression in the family members of cancer patients moved toward null (Table S1). This tendency is likely to require further study with a different design.

A second limitation is that depression might depend on the relationship between the cancer patient and the family members. This study assumed that all family members of cancer patients have the same burden. Although this study defined family members as only those who lived together during the survey time, cohabitation or contributions to the patient's care may change if cancer patients remain alive for a long time. Nevertheless, our results can still be meaningfully interpreted as suggesting that diagnosed depression may be related to simply being a family member of a cancer patient.

A third limitation is that we analyzed the total population, not only the family members of cancer patients, and the results showed risk factors for depression after adjusting for the family member's status. Therefore, we cannot be sure which risk factors are themselves associated with depression. In our data, the total number of family members of a cancer patient was insufficient for an analysis of this issue (Table S2). In future studies, it will be necessary to analyze the results using only the family members to evaluate the risk factors associated with being a caregiver.

Despite the aforementioned limitations, this study has strengths. First, we used nationally representative data and a large number of subjects. In summary, the results of this study show an association between having been diagnosed with depression and being a family member of a cancer patient in Korea. In addition, by defining depression based on a physician's diagnosis, rather than by measuring the extent of depression symptoms, we investigated the influence of the variables that incur actual medical costs to society from families with cancer patients.

This study found that the family members of cancer patients were more likely to have been diagnosed with depression. We need to invest more effort into diagnosing and managing depression in family members of cancer patients. This will have an impact both on their OoL and on the well-being of patients, as supporters and caregivers play an instrumental role in helping patients manage their illness.

\section{CONFLICT OF INTEREST}

The authors have no conflicts of interest associated with the material presented in this paper.

\section{SUPPLEMENTAL MAERIALS}

Supplemental Material 1: Table S1 is available at https:// www.jpmph.org/.

Supplemental Material 2: Table S2 is available at https:// www.jpmph.org/.

\section{ORCID}

Youngdae Cho http://orcid.org/0000-0003-1574-0012

Yongwoo Jeon https://orcid.org/0000-0002-0659-4159

Eun-Cheol Park http://orcid.org/0000-0002-2306-5398

\section{REFERENCES}

1. Torre LA, Bray F, Siegel RL, Ferlay J, Lortet-Tieulent J, Jemal A. Global cancer statistics, 2012. CA Cancer J Clin 2015;65(2):87108. 
2. Verdecchia A, Guzzinati S, Francisci S, De Angelis R, Bray F, Allemani $C$, et al. Survival trends in European cancer patients diagnosed from 1988 to 1999. Eur J Cancer 2009;45(6):10421066.

3. Ferlay J, Soerjomataram I, Dikshit R, Eser S, Mathers C, Rebelo $\mathrm{M}$, et al. Cancer incidence and mortality worldwide: sources, methods and major patterns in GLOBOCAN 2012. Int J Cancer 2015;136(5):E359-E386.

4. Global Burden of Disease Cancer Collaboration, Fitzmaurice $C$, Dicker D, Pain A, Hamavid H, Moradi-Lakeh M, et al. The global burden of cancer 2013. JAMA Oncol 2015;1(4):505-527.

5. Stenberg U, Ruland CM, Miaskowski C. Review of the literature on the effects of caring for a patient with cancer. Psychooncology 2010;19(10):1013-1025.

6. Bultz BD, Speca M, Brasher PM, Geggie PH, Page SA. A randomized controlled trial of a brief psychoeducational support group for partners of early stage breast cancer patients. Psychooncology 2000;9(4):303-313.

7. Carlson LE, Ottenbreit N, St Pierre M, Bultz BD. Partner understanding of the breast and prostate cancer experience. Cancer Nurs 2001;24(3):231-239.

8. Adelman RD, Tmanova LL, Delgado D, Dion S, Lachs MS. Caregiver burden: a clinical review. JAMA 2014;311(10):1052-1060.

9. Park B, Kim SY, Shin JY, Sanson-Fisher RW, Shin DW, Cho J, et al. Suicidal ideation and suicide attempts in anxious or depressed family caregivers of patients with cancer: a nationwide survey in Korea. PLoS One 2013;8(4):e60230.

10. Kim Y, Spillers RL. Quality of life of family caregivers at 2 years after a relative's cancer diagnosis. Psychooncology 2010;19(4): 431-440.

11. Kim Y, Spillers RL, Hall DL. Quality of life of family caregivers 5 years after a relative's cancer diagnosis: follow-up of the national quality of life survey for caregivers. Psychooncology 2012;21(3):273-281.

12. Goren A, Gilloteau I, Lees M, DaCosta Dibonaventura M. Quantifying the burden of informal caregiving for patients with cancer in Europe. Support Care Cancer 2014;22(6):1637-1646.

13. Edwards B, Clarke V. The psychological impact of a cancer diagnosis on families: the influence of family functioning and patients' illness characteristics on depression and anxiety. Psychooncology 2004;13(8):562-576.

14. Lee Y, Lin PY, Chien CY, Fang FM. Prevalence and risk factors of depressive disorder in caregivers of patients with head and neck cancer. Psychooncology 2015;24(2):155-161.

15. Park B, Kim SY, Shin JY, Sanson-Fisher RW, Shin DW, Cho J, et al. Prevalence and predictors of anxiety and depression among family caregivers of cancer patients: a nationwide survey of patient-family caregiver dyads in Korea. Support Care Cancer 2013;21(10):2799-2807.

16. Yoon SJ, Kim JS, Jung JG, Kim SS, Kim S. Modifiable factors associated with caregiver burden among family caregivers of terminally ill Korean cancer patients. Support Care Cancer 2014;22(5):1243-1250.

17. Song JI, Shin DW, Choi JY, Kang J, Baik YJ, Mo H, et al. Quality of life and mental health in family caregivers of patients with terminal cancer. Support Care Cancer 2011;19(10):1519-1526.

18. Rhee YS, Yun YH, Park S, Shin DO, Lee KM, Yoo HJ, et al. Depression in family caregivers of cancer patients: the feeling of burden as a predictor of depression. J Clin Oncol 2008;26(36): 5890-5895.

19. Price MA, Butow PN, Costa DS, King MT, Aldridge LJ, Fardell JE, et al. Prevalence and predictors of anxiety and depression in women with invasive ovarian cancer and their caregivers. Med J Aust 2010;193(5 Suppl):S52-S57.

20. Woźniak K, lżycki D. Cancer: a family at risk. Prz Menopauzalny 2014;13(4):253-261.

21. Kim Y, Shaffer KM, Carver CS, Cannady RS. Prevalence and predictors of depressive symptoms among cancer caregivers 5 years after the relative's cancer diagnosis. J Consult Clin Psychol 2014;82(1):1-8.

22. Oechsle K, Goerth K, Bokemeyer C, Mehnert A. Anxiety and depression in caregivers of terminally ill cancer patients: impact on their perspective of the patients' symptom burden. J Palliat Med 2013;16(9):1095-1101.

23. Pawl JD, Lee SY, Clark PC, Sherwood PR. Sleep loss and its effects on health of family caregivers of individuals with primary malignant brain tumors. Res Nurs Health 2013;36(4):386399.

24. Braun M, Mikulincer M, Rydall A, Walsh A, Rodin G. Hidden morbidity in cancer: spouse caregivers. J Clin Oncol 2007; 25(30):4829-4834.

25. Miaskowski C, Kragness L, Dibble S, Wallhagen M. Differences in mood states, health status, and caregiver strain between family caregivers of oncology outpatients with and without cancer-related pain. J Pain Symptom Manage 1997;13(3):138147.

26. Lim SM, Kim HC, Lee S. Psychosocial impact of cancer patients on their family members. Cancer Res Treat 2013;45(3):226233.

27. Han MA. Stress and depressive symptoms in cancer survivors 
and their family members: Korea Community Health Survey, 2012. Int J Environ Res Public Health 2017;14(9):999.

28. Jeon HJ. Epidemiologic studies on depression and suicide. J Korean Med Assoc 2012;55(4):322-328 (Korean).

29. Grunfeld E, Coyle D, Whelan T, Clinch J, Reyno L, Earle CC, et al. Family caregiver burden: results of a longitudinal study of breast cancer patients and their principal caregivers. CMAJ 2004;170(12):1795-1801.

30. Yang X, Wang L, He J, Ge C, Chang Y, Fu J, et al. Factors related to depressive symptoms among Chinese caregivers of cancer patients. Psychooncology 2012;21(10):1063-1070.

31. Chung ML, Pressler SJ, Dunbar SB, Lennie TA, Moser DK. Predictors of depressive symptoms in caregivers of patients with heart failure. J Cardiovasc Nurs 2010;25(5):411-419.

32. Al-Zahrani R, Bashihab R, Ahmed AE, Alkhodair R, Al-Khateeb $\mathrm{S}$. The prevalence of psychological impact on caregivers of hospitalized patients: the forgotten part of the equation. Qatar Med J 2015;2015(1):3.

33. Tramonti F, Bongioanni P, Leotta R, Puppi I, Rossi B. Age, gender, kinship and caregiver burden in amyotrophic lateral sclerosis. Psychol Health Med 2015;20(1):41-46.

34. Chumbler NR, Grimm JW, Cody M, Beck C. Gender, kinship and caregiver burden: the case of community-dwelling memory impaired seniors. Int J Geriatr Psychiatry 2003;18(8):722732.

35. Kim EY, Cho E, Lee NJ. Effects of family caregivers on the use of formal long-term care in South Korea. Int Nurs Rev 2013; 60(4):520-527.

36. Kim SH, Kim YL, Kim KW, Kim KH. The health behavior of single adult households in Korean over 30: the 6th Korean National Health and Nutrition Examination Survey. Korean J Fam Pract 2017;7(3):30-336 (Korean). 